\title{
Down-Regulation of Laminin-5 in Breast Carcinoma Cells
}

\author{
Katherine J. Martin,' Chi-Pong Kwan,' Koichi Nagasaki, \\ Xiaohong Zhang, ' Michael J. O'Hare, ${ }^{2}$ Carolyn M. Kaelin, ${ }^{3}$ \\ Robert E. Burgeson, ${ }^{4}$ Arthur B. Pardee, ${ }^{1}$ and Ruth Sager ${ }^{1}$ \\ ${ }^{1}$ Division of Cancer Genetics, Dana-Farber Cancer Institute and \\ Harvard Medical School, Boston, Massachusetts, U.S.A. \\ ${ }^{2}$ LICR/UCL Breast Cancer Laboratory, Department of Surgery, UCL \\ Medical School, London, U.K. \\ ${ }^{3}$ Department of Surgery, Comprehensive Breast Health Center, \\ Brigham and Womens Hospital, Boston, Massachusetts, U.S.A. \\ ${ }^{4}$ Departments of Dermatology and Anatomy and Cellular Biology, \\ Massachusetts General Hospital and Harvard Medical School, \\ Charlestown, Massachusetts, U.S.A.
}

Communicated by A. Pardee. Accepted July 18, 1998.

\begin{abstract}
Background: Laminin-5 (ln-5), a large heterotrimeric glycoprotein consisting of an $\alpha 3, \beta 3$, and $\gamma 2$ chain, is a component of epithelial cell basement membranes that functions as a ligand of the $\alpha 3 \beta 1$ and $\alpha 6 \beta 4$ integrins to regulate cell adhesion, migration, and morphogenesis. The ln-5 chains show tissue-specific patterns of regulation in tumors derived from different tissues. For example, $\ln -5$ is often up-regulated in gliomas, gastric carcinomas, and squamous carcinomas and down-regulated in prostate and basal cell carcinomas. Ln-5 expression patterns may represent useful tumor markers and help to elucidate the role of $\ln -5$ in tumor progression in different tissue types.

Materials and Methods: We have studied ln-5 expression patterns in the breast. mRNA levels were examined in tumor and normal breast epithelial cell lines, tissue samples, and immunomagnetically sorted primary cultures using differential display, Northern blotting, and hybridization arrays. Protein levels were examined by immunoprecipitation. Gene integrity was assessed by Southern blotting of representative cell types.

Results: Ln-5 $\alpha 3, \beta 3$, and $\gamma 2$ mRNA expression was found to be markedly down-regulated in a panel of breast tumor cell lines when compared with normal
\end{abstract}

breast epithelial cells. Ln-5 mRNA was expressed at relatively high levels in MCF-10A immortal normal breast epithelial cells, long-term cultures of normal breast cells, and sorted primary cultures of normal breast luminal epithelial and myoepithelial cells. Reduced, but detectable, levels of $\ln -5$ tended to be expressed in cell lines derived from early-stage breast tumors, whereas expression was generally not detected in cell lines derived from later-stage tumors. In breast tumor tissue specimens, expression of $\ln \alpha 3$ and $\beta 3$ mRNAs tended to be reduced relative to levels observed in adjacent nontumor tissue, whereas in $\gamma 2$ levels were elevated in specimens with increased amounts of myoepithelial cells. These ln-5 expression changes could not be attributed to large-scale mutations or gene rearrangements. Ln-5 protein levels were found to reflect mRNA levels in representative cell lines. At senescence, a growth state believed to suppress tumorigenesis, expression of all three $\ln -5$ mRNAs was up-regulated.

Conclusion: The down-regulation of $\ln -5$ mRNA expression in breast tumors cells provides a new molecular marker and suggests that $\ln -5$ functions to control tumor progression in the breast. 


\section{Introduction}

Laminin-5 (ln-5; previously called epiligrin, kalinin, nicein, and ladsin) is a large basement membrane glycoprotein involved in anchoring, functional determination, and migration of certain epithelial cells. It is a heterotrimeric protein composed of an $\alpha 3, \beta 3$, and $\gamma 2$ chain, which represent the products of three different genes (1). The molecule binds to and functions as a ligand for the desmosomal integrin $\alpha 6 \beta 4$, as well as the focal adhesion integrin $\alpha 3 \beta 1$ (2-5).

The role of $\ln -5$ in adhesion was first noted by the rounding and detachment of adherent cultured epithelial cells induced by mAb BMI65, an antibody to the $\ln \alpha 3$ chain (6). Mutations in any of the three $\ln -5$ chains can cause Herlitz syndrome (H-JEB), a severe form of the blistering skin disease junctional epidermolysis bullosa, in which the squamous epithelium detaches from underlying mesenchyme (7-9). The morphogenic activity of $\ln -5$ has been recently observed in experiments involving MCF-10A mammary epithelial cells. Antibodies that block the function of $\ln -5$ inhibited hemidesmosome assembly and the branching morphogenesis induced by matrigel (10).

The role of $\ln -5$ in cellular migration appears enigmatic. In multiple studies $\ln -5$ has been described as a strong migration-promoting factor (11-15), whereas in other studies it has been shown to act as a locomotion brake $(16,17)$. For example, a protein originally named ladsin and subsequently found to be identical to $\ln -5$ (18), induced the attachment and migration of a wide variety of cell lines including nontumorigenic epithelial, endothelial, and fibroblastic cell lines and several cancer cell lines $(12,19)$. On the other hand, cultured H-JEB keratinocytes with a homozygous null ln $\gamma 2$ gene have been reported to exhibit enhanced motility in vitro, which is then reduced in transfected cells that re-express $\ln \gamma 2$ (16). Since cell migration is a complex

Chi-Pong Kwan's present address is Massachusetts Institute of Technology, Bldg. 16-560, 77 Massachusetts Avenue, Cambridge, MA 02139, U.S.A.

Koichi Nagasaki's present address is Growth Factor Division, National Cancer Center Research Institute, 5-1-1 Tsukiji, Chuo-ku, Tokyo 104, Japan.

Ruth Sager is deceased.

Address correspondence and reprint requests to: Dr. Katherine J. Martin, Division of Cancer Biology, DanaFarber Cancer Institute and Harvard Medical School, 44 Binney Street, Boston, MA 02115, U.S.A. Phone: (617) 632-4685; Fax: 617)623-4680; E-mail: kmartin@ mbcrr.harvard.edu process that involves a series of attachment and disengagement events, different aspects of the process may have been observed in the different studies. Recent work, which may tie together these apparently contradictory reports, has shown that the treatment of a ln-5 matrix with metalloproteinase 2 (MMP-2) or with tissue-type plasminogen activator (tPA) modifies $\ln -5$ and changes its migratory properties $(11,20)$. MMP- 2 cleaves the $\ln \gamma 2$ chain to expose a putative cryptic migratory signal (11), while tPA cleaves the $\ln \alpha 3$ chain to generate a form of $\ln -5$ that supports hemidesmosome assembly and inhibits motility (20). These proteases have tissue-specific patterns of expression that may explain the different functional consequences of $\ln -5$ expression (20).

Ln-5 also appears to play dual roles in tumor progression. In gliomas and in carcinomas of the colon, gastric system, and squamous epithelium, it has been described as a highly expressed narker for the proliferating tumor cells that are located at the invasive edge of the tumor (15,21-23). Its expression was induced in cell lines derived from these tumor types by the tumor promoters tissue plasminogen activator (TPA) and epidermal growth factor (EGF) (18). On the other hand, in basal cell and prostate carcinomas, $\ln -5$ expression has been reported to be reduced relative to normal tissue $(24-26)$.

Here we report the results of studies on the expression of $\ln -5$ in normal breast epithelial cells and breast carcinomas. Using the differential display (DD) technique (27), we have previously reported the isolation of approximately 100 genes expressed in normal breast epithelial cells but not in breast tumor cells $(28,29)$. The $\ln -5$ chains were isolated as a part of this study, linking the protein with many genes involved in maintaining the phenotype of normal breast epithelial cells. Here we show that marked downregulation of $\ln \alpha 3$ and $\beta 3$ expression accompanied tumor formation in the breast, both in cultured cell lines and in tissue specimens. Further, all three $\ln -5$ chains were up-regulated in senescent breast epithelial cells, a growth state believed to suppress tumorigenesis (30-32). These results suggest that $\ln -5$ expression is detrimental to the process of tumor progression in the breast and that the down-regulation of the ln $\alpha 3$ and $\beta 3$ chains may provide useful markers for breast carcinoma. 


\section{Materials and Methods}

Cells, Cell Lines, and Culture Conditions

Human breast epithelial cells were sorted from primary cultures of breast mammoplasty specimens using a combination of calcium-free medium and immunomagnetic separation techniques (33). Normal breast epithelial cell strains $81 \mathrm{~N}, 76 \mathrm{~N}$, and $70 \mathrm{~N}$ were isolated from mammoplasty specimens (34). To prepare quiescent cells, $76 \mathrm{~N}$ cells were plated at approximately $15 \%$ confluence and grown to confluence. To prepare senescent cells, $76 \mathrm{~N}$ cells were passaged until proliferation ceased, for 20 to 22 passages. The $21 \mathrm{~T}$ series, $21 \mathrm{NT}, 21 \mathrm{PT}, 21 \mathrm{MT}-1$, and $21 \mathrm{MT}-2$, represent a mammary tumor progression series derived from the same patient (35). The breast tumor cell lines ZR-75-1, MCF-7, BT-474, BT$549, \mathrm{~T}-47 \mathrm{D}$, the MDA-MB series, including 157 , $231,361,435,436$, and 468, and the immortalized normal cell line MCF-10A were obtained from the American Type Culture Collection (Rockville, MD). All cell lines were cultured on plastic in DFCI-1 medium (34).

\section{Differential Display (DD) Analysis}

DD was performed as described $(29,36,37)$ to compare (1) normal, senescent, and quiescent $76 \mathrm{~N}$ breast cells, (2) 76N normal and MDA-MB435 breast tumor cells, or (3) normal sorted luminal epithelial, myoepithelial, and MDA-MB435 breast tumor cells. RNA was extracted by the Cs cushion centrifugation method (38). DD polymerase chain reactions (PCR) were performed using combinations of three 21 -bp anchor primers LH- ${ }_{11} \mathrm{~N}$ and twelve 18-bp LH-AP or ten 20to 21-bp extended OPA arbitrary primers (36). PCR products were electrophoresed using the GenomyxLR programmable sequencer (Genomyx, Foster City, CA).

Two $\ln \alpha 3$ gene tags were selected as DD bands that were up-regulated in senescent cells and down-regulated in quiescent cells derived from the normal $76 \mathrm{~N}$ breast cell strain. They were cloned as described (22). PCR-amplified DD-band DNA was ligated into a cloning vector using the Original TA cloning Kit (InVitrogen, San Diego CA), and DNA was prepared from selected clones and sequenced by automated methods (Applied Biosystems Inc. Sequencer, Dana-Farber Core Facility). Five ln $\beta 3$ gene tags were selected as DD bands expressed in cultured $76 \mathrm{~N}$ or primary cultures of myoepithelial and luminal epithelial cells, but absent from cultured cells of the metastatic MDA-MB-435 tumor cell line (29). Two of these, $\beta 3-A$ and $\beta 3-B$, were cloned and sequenced as described (37).

\section{Northern Analysis}

Northern blotting was performed as described previously (39). Ten micrograms of total cellular RNA was electrophoresed on agarose gels and transferred to nylon membranes. Membranes were hybridized overnight at $42^{\circ} \mathrm{C}$ then washed three times, 15 min per wash, in $2 \times$ SSC with $0.1 \%$ SDS at $50^{\circ} \mathrm{C}$.

\section{Southern Analysis of Genomic DNA}

Southern blotting was performed as described previously (39) after digesting high-molecularweight DNA isolated from cultured cells with HindIII. DNA was processed for Southern blotting and hybridized to a mixture of three probes $(\alpha 2-\mathrm{B}, \alpha 3-\mathrm{C}$, and $\alpha 3-\mathrm{D})$, which together cover $43 \%$ of the $L A M A 3$ gene (Fig. 1).

\section{Metabolic Labeling and Immunoprecipitation}

Metabolic labeling and immunoprecipitation were performed as described previously (40) using the $\ln \alpha 3$-specific monoclonal antibody BM-2 (also called BM165) (6) and the $\beta 3$-specific antibody 6F12 (also called K140) (41). 70N and MDA-MB-435 cells were grown to $70 \%$ confluency in DFCI-1 medium. Cells were washed with cys-, met-free DFCI-1 medium (custom synthesis, Gibco/BRL, Gaithersbury, MD), then incubated in the same medium supplemented with $50 \mu \mathrm{Ci} / \mathrm{ml}{ }^{35} \mathrm{~S}$-met and $20 \mu \mathrm{Ci} / \mathrm{ml}^{35} \mathrm{~S}$-cys (Express Labeling Mix, DuPont/NEN). Spent medium was removed and monolayers were lysed, scraped, and homogenized in a teflon pestle Dounce. Protein concentrations were determined. Media and lysate volumes were then adjusted with phosphate-buffered saline (PBS) to normalize protein concentrations. Equal volumes were precleared with Protein A-conjugated Sepharose 4B beads (BioRad, Hercules, CA) and $\ln -5$ was immunoprecipitated using Protein A-conjugated Sepharose 4B beads prebound to the specific antibody. Immunoprecipitated material was subsequently reduced and electrophoresed on 5\% acrylamide SDS gels.

\section{Hybridization Array Analysis}

Hybridization array analysis involved fixing DNA fragments to replicate nylon membranes in a 


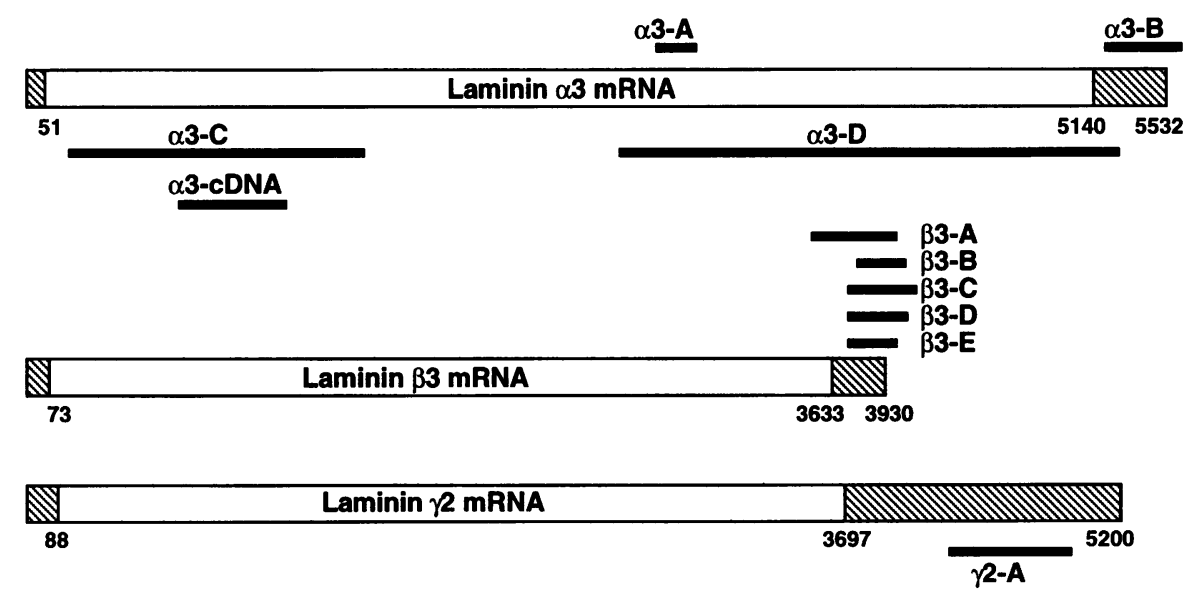

Fig. 1. Diagram of $\ln \alpha 3, \beta 3$, and $\gamma 2$ mRNAs showing locations of gene tags/probes. Tags isolated by differential display are shown above respective mRNAs. Tags below mRNAs were generated by RT/PCR using primers designed to hybridized to published sequences $(\alpha 3-\mathrm{C}, \alpha 3-\mathrm{D}, \gamma 2-\mathrm{A})$ or cloned

96-well format and then hybridizing membranes with ${ }^{32} \mathrm{P}$-labeled cDNA prepared in parallel from RNA extracted from comparison cell types. The procedure was performed as described elsewhere (29). Breast tumor and adjacent normal tissue specimens of approximately $100 \mathrm{mg}$ were obtained immediately following mastectomy or lumpectomy and frozen in liquid $\mathrm{N}_{2}$. Thawed tissue was minced into pieces of approximately 1 $\mathrm{mm}^{3}$, then homogenized in $3 \mathrm{ml}$ GUT- $\beta$ ME solution (4 M guanidine isothiocyanate, $25 \mathrm{mM}$ NaCitrate, $7 \mu \mathrm{l} / \mathrm{ml} \beta$-mercaptoethanol, $\mathrm{pH}$ 7) using 3 to 4 strokes of a teflon pestle Dounce. RNA was extracted by the Cs cushion centrifugation method (38).

\section{Results}

$D D$ Isolation of $\operatorname{Ln} \alpha 3$ and $\beta 3$ Gene Tags

Two tags for $\ln \alpha 3$ mRNA and five for $\ln \beta 3$ were isolated by DD. The $\ln \alpha 3$ gene tags were isolated from comparisons of normal, senescent, and quiescent $76 \mathrm{~N}$ breast cells. They were up-regulated in senescent and down-regulated in quiescent cells relative to the normal breast epithelial cells. Two of the $\ln \beta 3$ gene tags were isolated for comparisons of $76 \mathrm{~N}$ normal and MDA-MB-435 breast tumor, and the other three were isolated from comparisons of normal sorted luminal epithelial, myoepithelial, and MDA-MB-435 breast tumor cells. They were highly expressed in the from an expression library ( $\alpha 3$-cDNA) $(42,43,57)$. The total lengths of 5532 for the $\ln \alpha 3$ and 5200 for the ln $\gamma 2$ transcript account for all sequences reported $(7,42,43,57)$. The $3930 \mathrm{bp}$ of $\ln \beta 3$ is as reported (58).

normal cell types relative to the tumor cells. The five gene tags are referred to as $\alpha 3-\mathrm{A}, \alpha 3-\mathrm{B}$, and $\beta 3-A$ through $\beta 3-E$. The regions of the $\ln -5$ genes represented by these tags are shown in Figure 1. Three additional $\ln \alpha 3$ gene tags were also obtained for use as control probes. The $\alpha 3-\mathrm{C}$ and $\alpha 3-\mathrm{D}$ tags were produced by RT-PCR from 76N RNA using synthetic primers designed to hybridize at the indicated locations. The $5^{\prime}$ primer of $\alpha 3-C$ is predicted to specifically recognize the $\alpha 3_{\mathrm{EpA}}$ transcript (42). This transcript is the smaller of two produced from the LAMA3 gene. $\alpha 3-\mathrm{cDNA}$ represents a $570 \mathrm{bp}$ region of the ln $\alpha 3$ cDNa, from nucleotide 706-1276 (42). A In $\gamma 2$ tag, $\gamma 2$-A, was prepared by RT-PCR from $76 \mathrm{~N}$ RNA using two primers designed to hybridize to the indicated locations of the ln $\gamma 2$ cDNA (Fig. 1). Both primers were designed to recognize only the longer of two different transcripts produced from the LAMC3 $(42,43)$.

\section{Expression of Ln-5 mRNA in Normal Breast Epithelial Cells}

To assess expression in normal breast epithelial cells, RNA from the immortalized normal breast epithelial cell line MCR-10A and the normal breast epithelial cell strain $76 \mathrm{~N}$ were tested by Northern blotting. The morphology of MCF-10A cells is characteristic of breast luminal epithelial cells (44), whereas $76 \mathrm{~N}$ cells express predominantly myoepithelial cell markers (45). Expres- 


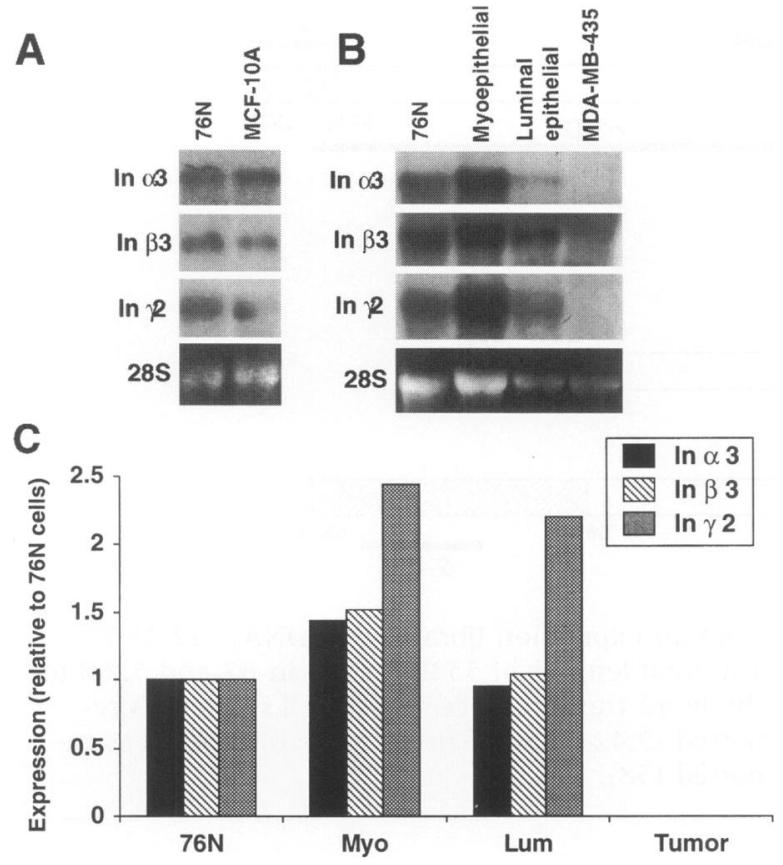

Fig. 2. Expression of $\ln -5$ mRNAs in normal breast epithelial cells. (A) Expression of $\ln -5$ mRNAs in cultured normal breast epithelial cells, $76 \mathrm{~N}$ and MCF-10A, assayed by Northern blotting. Ethidium bromide-stained 28S rRNA is a loading control. (B) Northern blotting of $\ln -5$ mRNAs in breast luminal epithelial and myoepithelial cells immunomagnetically sorted from primary cultures of normal breast tissue. Normal cultured $76 \mathrm{~N}$ cells and the MDA-MB-435 breast tumor cell line are shown for comparison. (C) Expression levels of ln-5 mRNAs in 76N cells, sorted normal luminal epithelial (Lum) and myoepithelial (Myo) cells, and MDA-MB-435 tumor cells. Bars indicate expression relative to levels in $76 \mathrm{~N}$ cells. Expression was normalized to the signal of ethidium bromide-stained 28S rRNA.

sion of all three ln-5 mRNAs was high in MCR$10 \mathrm{~A}$ cells and $76 \mathrm{~N}$ cells (Fig. $2 \mathrm{~A}$ ). Ln $\alpha 3, \beta 3, \gamma 2$ mRNA expression was also assayed in immunomagnetically sorted primary breast luminal epithelial and myoepithelial cells. Levels of expression of all three chains were comparable to those of $76 \mathrm{~N}$ epithelial cells in both epithelial cell types (Fig. 2B, C). Ln $\alpha 3$ and $\beta 3$ expression levels were tested in additional normal breast myoepitheliallike cells, $70 \mathrm{~N}$ and $81 \mathrm{~N}$, and levels were found to be high (Fig. 3A).

Breast luminal epithelial cells appear to be the cell type origin of breast carcinomas (ref. 46 and references therein), hence it is especially relevant that levels of expression of all three ln-5 mRNAs were high in the luminal epitheliallike cell line MCF10A and in sorted normal breast luminal epithelial cells. Ln-5 expression levels were equivalent in sorted populations of normal luminal epithelial and myoepithelial cells (Fig. 2B, C). To show that the sorted luminal epithelial cells did not contain significant numbers of myoepithelial cells, we have measured the expression of myoepithelial marker keratin 14. In repeated hybridization array assays, keratin 14 expression in luminal epithelial cells was $1 / 10$ to $1 / 30$ of the levels found in myoepithelial populations. Previous measurements assessing a variety of myoepithelial markers showed that breast luminal epithelial cells sorted in the same manner contained approximately $1 \%$ myoepithelial cells $(33,47)$. Hence, we conclude that the luminal epithelial cells truely expressed the ln-5 genes.

\section{Down-Regulation of Ln-5 Message Levels in Breast Tumor Cells}

Northern and hybridization array analyses were used to verify DD results, which indicated that ln $\beta 3$ mRNA expression is down-regulated in breast tumor cells. Expression of $\ln \alpha 3$ and $\gamma 2$ was also assayed. To assess levels in breast tumor cells, 15 cell lines derived from breast carcinomas were tested. Four of these tumor cell lines were derived from nonmetastatic primary tumors, BT474, BT549, 21NT, 21PT, while the remainder were derived from metastatic tumors. Ln $\alpha 3$ expression assayed by Northern blotting with probe $\alpha 3-\mathrm{A}$, showed that expression was very low or not detected in all 15 tumor cell lines (Fig. 3A). Very low levels of $\alpha 3$ expression were seen after long exposures in tumor cell lines MCF7, BT549, and T47D (data not shown). Hence, $\ln \alpha 3$ expression was low, but detectable, in the majority ( 3 of 4 ) of tumor cell lines derived from nonmetastatic primary tumors, and was not detected in the majority ( 7 of 11 ) of tumor cell lines derived from metastatic tumors. Results identical to those obtained with the $\alpha 3$-A probe were obtained using the $\alpha 3-\mathrm{B}$ and $\alpha 3-\mathrm{C}, \alpha 3-\mathrm{D}$ gene tags and the $\alpha 3$-cDNA as probes (data not shown). Comparable results were obtained using hybridization array analysis (Fig. 3B).

Expression of $\ln \beta 3$ mRNA was assayed in 14 breast tumor cell lines using the $\beta 3$-A probe. Expression was reduced in all tumor cell lines tested compared to that of the normal cells (Fig. 3A, B). Similar to $\alpha 3$, intermediate levels of expression of $\beta 3$ mRNA were observed in MCF7, BT-549, T47D, 21PT, 21NT, and 21MT-1 cells. Hence, $\ln \beta 3$ expression was intermediate in all 3 


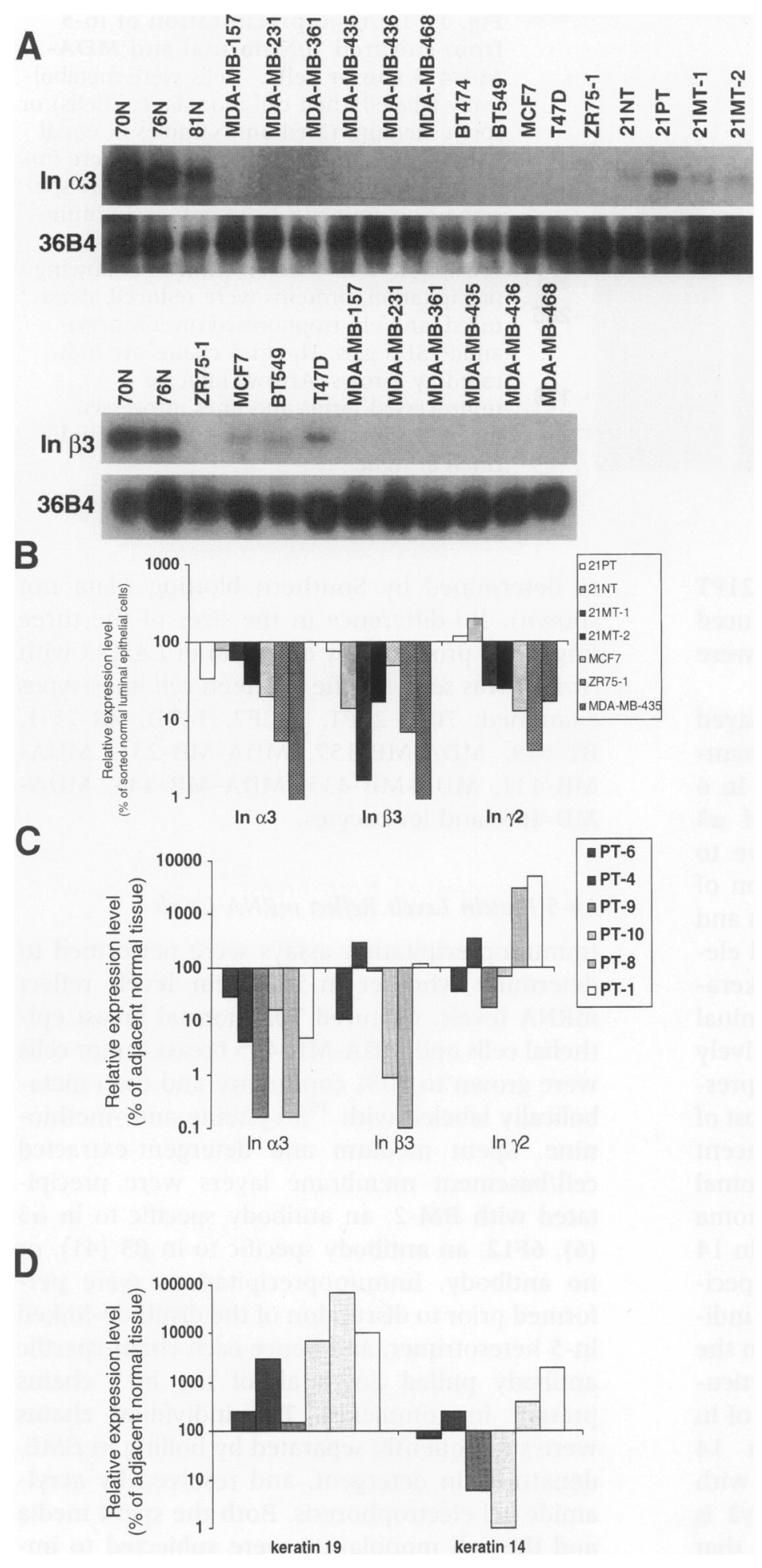

Fig. 3. Down-regulation of $\ln -5$ mRNAs in breast tumor cell lines and tissues. (A) Expression of $\ln \alpha 3$ and $\beta 3$ mRNAs in cultured normal breast epithelial cells $(70 \mathrm{~N}, 76 \mathrm{~N}$ and $81 \mathrm{~N})$ and breast tumor cell lines assayed by Northern blotting. 36B4 is loading control (59). (B) Expression of $\ln \alpha 3, \beta 3$, and $\gamma 2$ mRNAs in cultured breast tumor cell lines assayed using hybridization arrays. Bars indicate expression relative to levels in sorted primary cultures of normal breast luminal epithelial cells. Expression of 36B4 was used as a normalizing control as described previously (29). (C) Expression of ln-5 mRNAs in samples of breast tumor tissue assayed using hybridization arrays. Bars indicate expression in tumor samples relative to levels in adjacent normal breast tissue. Tumors are listed in order of increasing size. Sizes and AJCC clinical stage groups were as follows: PT-6, $1.2 \mathrm{~cm}$, stage II; PT-4, $2.0 \mathrm{~cm}$, stage II, PT-9, $2.5 \mathrm{~cm}$, stage II; PT- $10,2.5 \mathrm{~cm}$, stage III; PT- $8,4.5 \mathrm{~cm}$, stage III; PT- $1,8.0 \mathrm{~cm}$, stage IV. 36B4 expression was used as a normalizing control as described previously (29). (D) Expression of epithelial cell markers keratins 19 and 14 in breast tumor tissue samples relative to levels in adjacent normal tissue and assayed using hybridization arrays. Tumor samples and normalization are as for Figure 3C. of tumor cell lines tested that were derived from nonmetastatic primary tumors, and was reduced to levels not detected by Northern blotting in the majority (7 of 9) of tumor cell lines derived from metastatic tumors.
Expression of ln $\gamma 2$ mRNA was assayed in 7 breast tumor cell lines by hybridization array assay using the $\gamma 2$-A DNA fragment as a gene tag. Ln $\gamma 2$ expression was similar to that of normal cells in two cell lines derived from a non- 


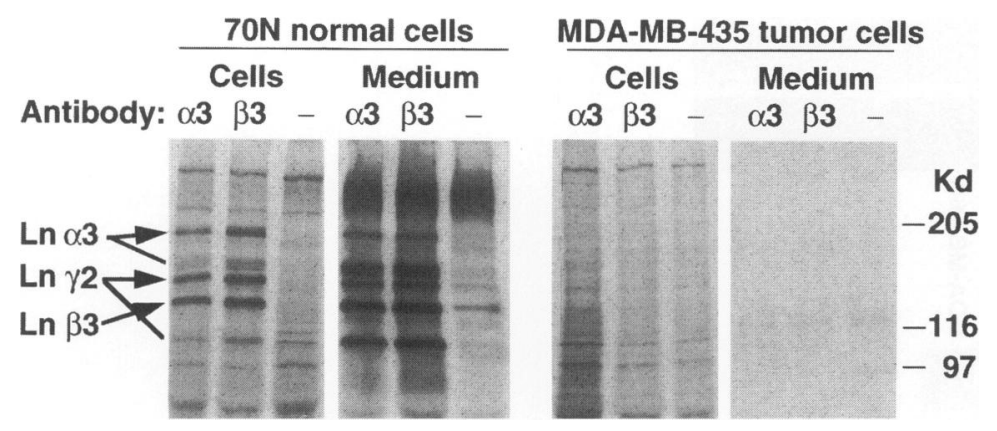

Fig. 4. Immunoprecipitation of $\ln -5$ from cultured 70N normal and MDAMB-435 tumor cells. Cells were metabolically labeled, then cell monolayer (Cells) or spent medium (Medium) samples of equal volume and protein concentration were immunoprecipitated using $\alpha 3$-specific, $\beta 3$-specific or no antibody, as indicated. Immunoprecipitations were performed prior to disruption of $\ln -5$ heterotrimers. Following precipitation, proteins were reduced, denatured, and electrophoresed on 5\% acrylamide SDS gels. The $\ln -5$ chains are indicated by arrows. Arrows indicate unprocessed forms and lines, processed forms. Positions of size standards are indicated at right. metastatic primary tumor, 21NT and 21PT (Fig. 3B). $\gamma 2$ expression was markedly reduced in the other 5 tumor cell lines tested, which were all derived from metastatic breast tumors.

Ln-5 mRNA expression levels were assayed in breast tumor and adjacent normal tissue samples using the hybridization array method. In 6 of 6 tumor samples tested, expression of $\alpha 3$ mRNA was reduced at least 3 -fold relative to adjacent normal tissue (Fig. 3C). Expression of $\beta 3$ mRNA was reduced in 3 of the 6 samples and expression $\gamma 2$ mRNA was reduced in 1 and elevated in 2 of the 6 samples. Expression of keratins 19 and 14, which are markers of luminal epithelial and myoepithelial cells, respectively (48), were also assayed. As expected, the expression of keratin 19 mRNA was elevated in most of the tumor tissue samples relative to adjacent normal tissue (Fig. 3D), reflecting the luminal epithelial-like characteristics of breast carcinoma cells (ref. 46 and references therein). Keratin 14 mRNA was overexpressed in some tumor specimens and underexpressed in others, likely indicating increases or decreases, respectively, in the percentage of myoepithelial cells in the particular tissue sample. Interestingly, the pattern of ln $\gamma 2$ mRNA expression paralleled keratin 14 mRNA expression levels. This is consistent with previously reported observations that $\ln \gamma 2$ is highly expressed in the myoepithelial cells that surround some breast carcinomas, but is not observed in the tumor cells themselves (23). Ln $\gamma 2$ is expressed at higher levels in the nonmalignant myoepithelial cells that surround some breast carcinomas than in myoepithelial cells not in contact with tumor cells (23).

Down-regulation of $L A M A 3$ gene expression was not due to gross alterations in gene structure as determined by Southern blotting (data not shown). No difference in the sizes of the three fragments produced by digestion of $L A M A 3$ with HindIII was seen for the fourteen cell lines/types examined: 70N, 21PT, MCF7, T47D, ZR-75-1, BT-549, MDA-MB-157, MDA-MB-231, MDAMB-431, MDA-MB-435, MDA-MB-436, MDA$\mathrm{MB}-468$, and leukocytes.

\section{Ln-5 Protein Levels Reflect mRNA Levels}

Immunoprecipitation assays were performed to determine whether $\ln -5$ protein levels reflect mRNA levels. Cultured $70 \mathrm{~N}$ normal breast epithelial cells and MDA-MB-435 breast tumor cells were grown to $50 \%$ confluence and then metabolically labeled with ${ }^{35} \mathrm{~S}$-cysteine and -methionine. Spent medium and detergent-extracted cell/basement membrane layers were precipitated with BM-2, an antibody specific to $\ln \alpha 3$ (6), 6F12, an antibody specific to $\ln \beta 3$ (41), or no antibody. Immunoprecipitations were performed prior to disruption of the disulfide-linked ln-5 heterotrimer, and hence each chain-specific antibody pulled down all of the $\ln -5$ chains present in complexes. The individual chains were subsequently separated by boiling in $\beta \mathrm{ME}$, denatured in detergent, and resolved by acrylamide gel electrophoresis. Both the spent media and the cell monolayers were subjected to immunoprecipitation.

From the cell monolayer fraction of normal breast $70 \mathrm{~N}$ cells, which also includes insoluble secreted basement membrane components, both antibodies precipitated proteins with molecular weights corresponding to the $\ln \alpha 3(190 \mathrm{kD}), \beta 3$ (140 kD), and $\gamma 2$ (155 kD) chains (6) (Fig. 4). Low levels of the processed $\alpha 3$ doublet (160 kD) 
and $\gamma 2(105 \mathrm{kD})$ chains were also present. Bands corresponding to these molecular weights were not present in control precipitations performed without antibody. From $70 \mathrm{~N}$ medium, immunoprecipitated proteins had the molecular weights expected for the intact and processed $\alpha 3$ chains, the $\beta 3$ chain, and the intact and processed $\gamma 2$ chain. In $70 \mathrm{~N}$ medium, the $\alpha 3$ and $\gamma 2$ chains were both partially processed (i.e., approximately $80 \%$ of $\alpha 3$ and $60 \%$ of $\gamma 2$ was present in processed forms). Processing of the $\alpha 3$ and $\gamma 2$ chains has previously been observed in cell culture. The medium of cultured keratinocytes contains $\ln -5$ with a totally processed $\alpha 3$ chain and a partially processed $\gamma 2$ chain (41), whereas colon cells produce unprocessed ln-5 (49). Hence, processing occurs to different extents in different cell types. These processing events have been shown to alter the functional consequences of $\ln -5$ $(11,20)$.

In contrast to the readily observed $\ln -5$ chains produced by the normal breast cells, only faint bands were observed following immunoprecipitation of MDA-MB-435 breast carcinoma cells (Fig. 4). In immunoprecipitations of the MDA-MB-435 cellular fraction, very low levels of the processed $160 \mathrm{kD} \beta 3$ chain were observed following immunoprecipitation with the $\alpha 3$-specific antibody. No $\ln -5$ proteins could be seen to be specifically immunoprecipitated by the $\beta 3$ antibody. No ln-5 was detected in the spent medium.

\section{Ln-5 mRNA Expression in Quiescent and Senescent Cells}

Since senescence has been described as a growth state that suppresses tumorigenesis (30-32), Northern analysis was performed to examine ln-5 mRNA expression in senescent, quiescent, and actively growing $76 \mathrm{~N}$ breast epithelial cells. Expression of $\ln \alpha 3$ was markedly reduced in quiescent cells and increased in senescent cells relative to activity growing cells (Fig. 5A). Results identical to those obtained with the $\alpha 3-\mathrm{A}$ probe were obtained using $\alpha 3-\mathrm{B}, \alpha 3-\mathrm{C}, \alpha 3-\mathrm{D}$, and $\alpha 3-\mathrm{cDNA}$ as probes (data not shown). Very strong up-regulation was also observed for $\gamma 2$ mRNA in senescent cells (Fig. 5A). Expression of $\beta 3$ mRNA was modulated similarly to $\alpha 3$, though to a lesser degree. To further investigate the decrease in $\ln \alpha 3$ expression in quiescent cells and the increase in senescent cells, time courses for both were examined. Ln $\alpha 3$ mRNA levels decreased by a factor of 100 as cells became more confluent (Fig. 5B) and increased 20-fold as cells aged (Fig. 5C).

\section{Discussion}

In previous studies, we have compared a variety of breast epithelial cell types and cell growth conditions using DD, and identified and verified over a hundred different differentially expressed genes $(28,29)$. In an effort to identify genes that confer the normal breast epithelial phenotype, we looked for genes expressed in normal breast epithelial cells and down-regulated in breast tumor cells. Many of the identified down-regulated genes are known to be involved in cell adhesion and communication events. For example, genes down-regulated in breast tumor cells included the basement membrane protein fibronectin, the cell membrane-associated proteins caveolin, $\alpha 6$ integrin, protocadherin, and connexins 26 and 43 , as well as the protease inhibitors $\alpha 1$ antichymotrypsin, plasminogen activator inhibitor PAI-2, cystatins A and M, elafin, and maspin. These proteins are all believed to be important in producing or maintaining stable cellular adhesion and intercellular communication. The isolation of In-5 as a part of this study links it with these normal-specific genes and implies that it plays a role in maintaining the phenotype of the normal breast epithelial cell.

The results presented here show that $\ln -5$ mRNA expression is down-regulated in breast tumor cells. A trend was observed for decreased expression of $\ln -5$ as tumors progressed. Expression levels tended to be lower in cell lines derived from later-stage, metastatic tumors than in cell lines derived from nonmetastatic primary tumors. In comparison, expression levels of all three $\ln -5$ mRNAs were high in normal breast epithelial cells, especially the MCF-10A cell line and immunomagnetically sorted normal breast luminal epithelial cells. These are relevant normal cell types for comparison with breast tumor cells, since both display molecular markers and morphological characteristics of normal luminal epithelial cells $(44,47)$, the cell type to which breast carcinomas are most similar $(46,50)$. Ln $\alpha 3$ and $\beta 3$ mRNAs also tended to be expressed at lower levels in patient breast tumor specimens relative to adjacent nontumor breast tissue. Further, the $\ln -5$ mRNAs were up-regulated at senescence, which has been described as a growth state that functions to suppress tumorigenesis $(30-32)$. Down-regulation of $\ln -5$ in this broad 


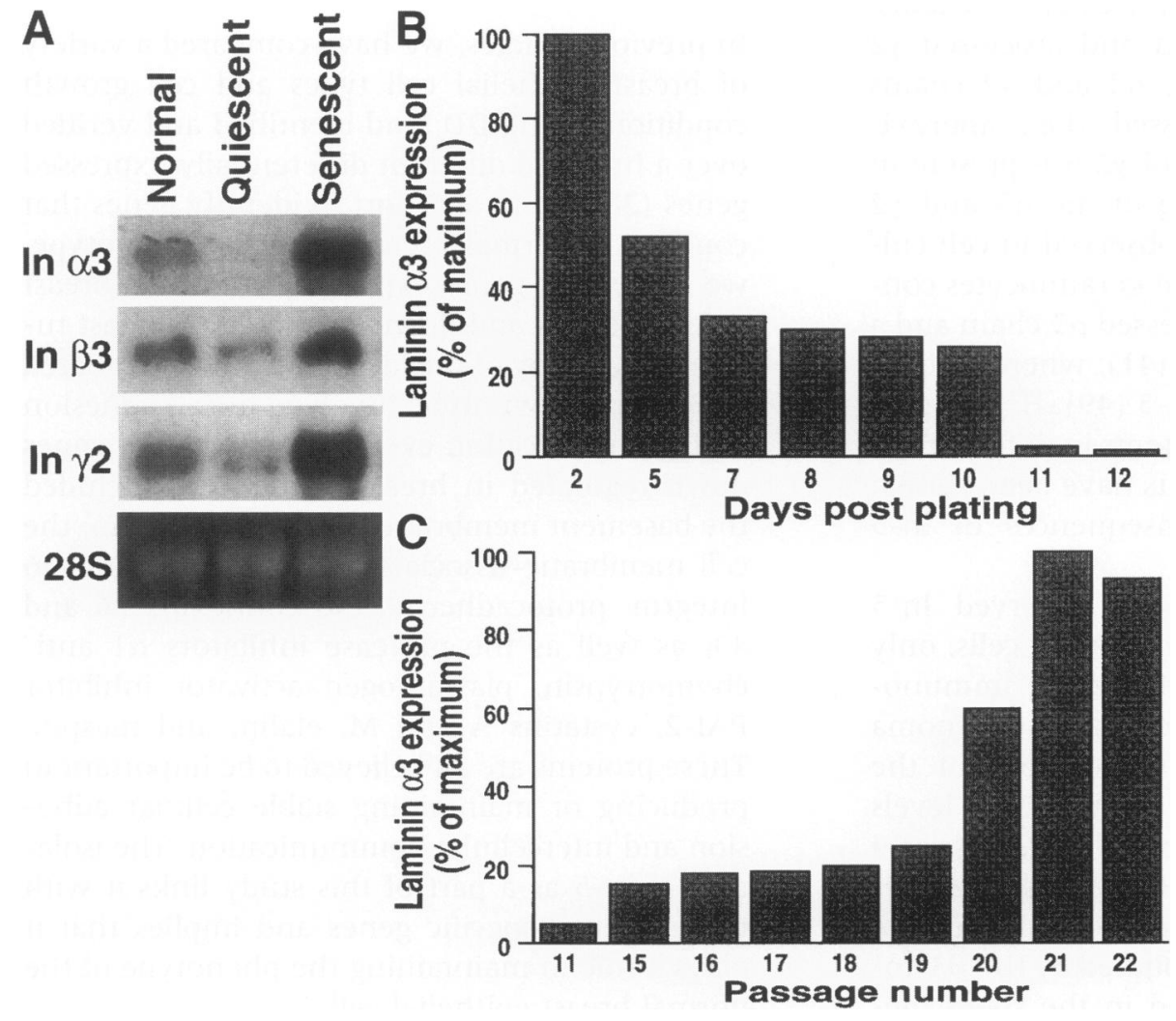

Fig. 5. Expression of ln-5 mRNAs in normal, quiescent, and senescent $76 \mathrm{~N}$ breast epithelial cells. (A) Normal RNA was isolated from passage $1176 \mathrm{~N}$ cells at $70 \%$ confluence, quiescent RNA was from confluent passage 11 $76 \mathrm{~N}$ cells, and senescent RNA was from $70 \%$ confluent passage $2276 \mathrm{~N}$ cells. Ethidium bromide-stained $28 \mathrm{~S}$ rRNA loading control is from membrane used for $\alpha 3$ blot and is representative of membranes used for $\beta 3$ and $\gamma 2$ blots. (B) Expression of $\ln \alpha 3$ mRNA as cells become quiescent. Passage $1176 \mathrm{~N}$ cells were plated at $30 \%$ confluence and allowed to grow on plates for 12 days. Bars represent ln $\alpha 3$ expression levels assayed by Northern blotting using probe $\alpha 3-\mathrm{A}$, quantified by densitometry, and normalized to 36B4 expression. (C) Expression of $\ln \alpha 3$ mRNA as cells senesce. $76 \mathrm{~N}$ cells at the indicated passage number were collected at $70 \%$ confluence. Expression was assayed and quantified as for Figure 5B. panel of tumor cell lines and patient tissue samples, and its up-regulation at senescence, implies that loss of $\ln -5$ expression may be functionally important for tumor progression in the breast. The changes in laminin-5 expression appear more relevant to the later stages of tumor progression rather than the initiating ones.

Consistent with our observation of $\ln -5$ down-regulation in breast carcinomas, other lines of research have indicated that inactivation of the ln-5 pathway is a common occurrence in breast cancer. Down-regulation of integrins $\alpha 3 \beta 1$ and $\alpha 6 \beta 4$ has been documented in breast cancer cells (e.g. ref. 51-53). Likewise, Howlett et al. (54) found that malignant breast cells continued to proliferate in the presence of antibodies that blocked the function of $\beta 1$ integrin, whereas these same antibodies induced apoptosis in normal epithelial cells.

Ln $\gamma 2$ expression has previously been observed at higher levels in the nonmalignant myoepithelial cells that surround some breast carci- nomas than in myoepithelial cells not in contact with tumor cells (23). This expression was proposed to represent a wounding response to the invading tumor and, as such, is in agreement with our observation that all of the $\ln -5$ chains are most highly expressed in actively proliferating cells. Another view of this increased expression of $\ln -5$ can also be proposed. Since the ln-5 expression pattern in the breast suggests a tumor-suppressing function, tumor-induced myoepithelial expression may represent a mechanism to control tumor progression. On the basis of several independent lines of evidence, normal myoepithelial cells have been hypothesized to provide an important host defense against breast tumor invasion (55).

Recent studies have examined ln-5 expression in carcinomas derived from various tissue types and have found that in some tissue types, expression is up-regulated, while in others it is down-regulated. In carcinomas of the colon, gastric system, and squamous epithelium, in situ 
immunostaining with an antibody specific to ln $\gamma 2$ showed elevated levels of expression, particularly in the invasive cells at the growing edge of the tumor $(15,22,23)$. Studies of tumor cell lines derived from stomach, tongue, and cervical carcinomas showed secretion of ladsin, a molecule recently found to be identical to $\ln -5(12,18,19)$. In contrast, $\ln -5$ levels in basal cell and prostate carcinomas have been reported to be reduced relative to levels of surrounding normal tissue $(24-26)$. We propose that the characteristic increase or decrease of $\ln -5$ expression in carcinomas derived from different tissue types may reflect different roles of the molecule in the different tissues.

Processing of the $\ln \alpha 3$ and $\gamma 2$ chains was observed to occur in cultured normal breast epithelial cells. Approximately $90 \%$ of the soluble $\ln \alpha 3$ and $\gamma 2$ was processed and $10 \%$ of the cell-associated $\ln \alpha 3$ and $\gamma 2$ was processed. Ln-5 $\alpha 3$ was processed from a $190 \mathrm{kD}$ to a $160 \mathrm{kD}$ form, while $\gamma 2$ was processed from a $155 \mathrm{kD}$ to a $105 \mathrm{kD}$ form. Similar processing of the $\alpha 3$ and $\gamma 2$ chains has been observed previously for keratinocytes (41). Ln-5 processing appears to be highly significant in determining its function, though the precise effects of the different processing events in the context of the in vivo cellular environment are not yet clear. Ln $\gamma 2$ processing by the matrix metalloprotease MMP-2 to generate an $80 \mathrm{kD}$ form has been shown to shift the ln- 5 matrix from a stationary to a migratory substrate for breast epithelial cells, apparently by exposing a cryptic migratory signal (11). In contrast, $\ln \alpha 3$ is processed by tPA to generate a $160 \mathrm{kD}$ molecule capable of nucleating hemidesmosome assembly and inhibiting cell motility (20). Consistent with our observation of a $160 \mathrm{kD} \alpha 3$ chain and no $80 \mathrm{kD} \gamma 2$ chain, $76 \mathrm{~N}$ cells are not highly motile under culture conditions identical to those of our study (56). In comparison, the breast tumor cell line MDA-MB-435, which we find does not produce detectable levels of $\ln -5$, is highly motile.

Processing of the $\ln -5$ chains occurs to different extents in different tissues. In the present study of breast cells, $\ln \alpha 3$ and $\gamma 2$ were both partially processed to 165 and $105 \mathrm{kD}$ forms, respectively. In cultured keratinocytes, virtually all $\ln \alpha 3$ is processed, whereas $\ln \gamma 2$ is present in both processed and unprocessed forms (1). In colon tumors, however, neither the $\ln \alpha 3$ nor the $\gamma 2$ chain are found in their processed form (49). It has been suggested that the characteristic absence of hemidesmosomes in colon tumors may result from the absence of these forms of $\ln -5$ (16). Differential processing of the $\ln -5$ chains in different tissues may determine the role the molecule plays in normal cellular processes and hence may impact the direction in which its expression is altered in tumors.

\section{Acknowledgments}

The authors thank Binh Troung for technical assistance, Carol Milbury for $\ln -5$ antibodies, and Don Gerecke for ln $\alpha 3$ cDNA. This study was funded by the Ludwig Institute for Cancer Research.

\section{References}

1. Burgeson RE, Chiquet $M$, Deutzman $R$, et al. (1994) A new nomenclature for the laminins. $M a$ trix Biol. 14:209-211.

2. Carter WG, Kaur P, Gil SG, Gahr PJ, Wayner EA (1990) Distinct functions for integrins $\alpha 2 \beta 1$ in focal adhesions and $\alpha 6 \beta 4$ /bullous pemphigoid antigen in a stable anchoring contact (SAC) of keratinocytes: relation to hemidesmosomes. J. Cell Biol. 111:3141-3145.

3. Wayner EA, Gil SG, Murphy GF, Wilke MS, Carter WG (1993) Epiligrin, a component of epithelial basement membranes, is an adhesive ligand for $\alpha 3 / \beta 1$ positive T lymphocytes. J. Cell Biol. 121: 1141-1152.

4. Niessen CM, Hogervorst F, Jaspars LH, et al. (1994) The $\alpha 6 \beta 4$ integrin is a receptor for both laminin and kalinin. Exp. Cell Res. 2111:360-367.

5. Gil SG, Brown TA, Ryan MC, Carter WG (1994) Junctional epidermolysis bullosis: defects in expression of epiligrin/nicein/kalinin and integrin beta 4 that inhibit hemidesmosome formation. J. Invest. Dermatol. 103:31S-38S.

6. Rousselle P, Lundstrum GP, Keene DR, Burgeson RE (1991) Kalinin: an epithelium-specific basement membrane adhesion molecule that is a component of anchoring filaments. J. Biol. Chem. 114: 567-576.

7. Vidal F, Baudoin C, Miquel C, et al. (1995) Cloning of the laminin alpha 3 chain (LAMA3) and identification of a homozygous deletion in a patient with Herlitz junctional epidermolysis bullosa. Genomics 30:273-280.

8. Pulkkinen L, Christiano AM, Gerecke D, Burgeson RE, Pittelkow MR, Uitto J (1994) A homozygous nonsense mutation in the $\beta 3$ chain gene of laminin 5 (LAMB3) in Herlitz junctional epidermolysis bullosa. Genomics 24:357-360.

9. Aberdam D, Galliano MF, Vailly J, et. al. (1994) Herlitz's junctional epidermolysis bullosa is linked to mutations in the gene $(L A M C 2)$ for the $\gamma 2$ sub- 
unit of nicein/kalinin (LAMININ-5). Nat. Genet. 6:299-304.

10. Stahl S, Weitzman S, Jones J (1997) The role of laminin-5 and its receptors in mammary epithelial cell branching morphogenesis. J. Cell Sci. 110:5563.

11. Gianelli G, Falk-Marzillier J, Schiraldi O, StatlerStevenson WG, Quaranta V (1997) Induction of cell migration by matrix metalloprotease-2 cleavage of laminin-5. Science 277:225-228.

12. Miyazaki K, Kikkawa Y, Nakamura A, Yasumitsu H, Umeda M (1993) A large cell-adhesive scatter factor secreted by human gastric carcinoma cells. Proc. Natl. Acad. Sci. U.S.A. 90:11767-1 1771.

13. Zhang K, Kramer RH (1996) Laminin 5 deposition promotes keratinocyte motility. Exp. Cell Res. 227: 309-322.

14. Tani T, Karttunen T, Kiviluoto T, Kivilaakso E, Burgeson RE, Sipponen P, Virtanen I (1996) Alpha 6 beta 4 integrin and newly deposited laminin-1 and laminin-5 form the adhesion mechanism of gastric carcinoma. Continuous expression of laminins but not that of collagen VII is preserved in invasive parts of the carcinomas: implications for acquisition of the invading phenotype. Am. J. Pathol. 149:781-793.

15. Tani T, Lumme A, Linnala A, et al. (1997) Pancreatic carcinomas deposit laminin-5, preferentially adhere to laminin-5, and migrate on the newly deposited basement membrane. Am. J. Pathol. 151:1289-1302.

16. Gagnoux-Palacios L, Vailly J, Durand-Clement M, Wagner E, Ortonne JP, Meneguzzi G (1996) Functional re-expression of laminin-5 in laminin-5 deficient human keratinocytes modifies cell morphology, motility, and adhesion. J. Biol. Chem. 271:18437-18444.

17. O'Toole EA, Marinkovich MP, Hoeffler WK, Furthmayr H, Woodley DT (1997) Laminin-5 inhibits human keratinocyte migration. Exp. Cell Res. 233:330-339

18. Mizushima H, Miyagi Y, Kikkawa Y, Yamanaka N, Yasumitsu H, Misugi K, Miyazaki K (1996) Differential expression of laminin-5/ladsin subunits in human tissues and cancer cell lines and their induction by tumor promoter and growth factors. J. Biochem. (Tokyo) 120:1 196-1202.

19. Kikkawa Y, Umeda M, Miyazaki K (1994) Marked stimulation of cell adhesion and motility by ladsin, a laminin-like scatter factor. J. Biochem. 116:862869.

20. Goldfinger LE, Stack MS, Jones JCR (1998) Processing of laminin-5 and its functional consequences: role of plasmin and tissue-type plasminogen activator. J. Cell Biol. 141:255-265.

21. Fukushima $Y$, Ohnishi T, Arita N, Hayakawa T, Sekiguchi K (1998) Integrin alpha3betal-mediated interaction with laminin-5 stimulates adhesion, migration and invasion of malignant glioma cells. Int. J. Cancer 76:63-72.
22. Pyke C, Romer J, Kallunki P, Lund LR, Ralfkiaer E, Dano K, Tryggvason K (1994) The gamma 2 chain of kalinin/laminin 5 is preferentially expressed in invading malignant cells in human cancers. Am. J. Pathol. 145:782-791.

23. Pyke C, Salo S, Ralfkiaer E, Romer J, Dano K, Tryggvason $\mathrm{K}$ (1995) Laminin-5 is a marker of invading cancer cells in some human carcinomas and is coexpressed with the receptor for urokinase plasminogen activator in budding cancer cells in colon carcinomas. Cancer Res. 55:4132-4139.

24. Bahadoran P, Perrin C, Aberdam D, SpadaforaPisani A, Meneguzzi G, Ortonne JP (1997) Altered expression of the hemidesmosome-anchoring filament complex proteins in basal cell carcinoma: possible role in the origin of peritumoral lacunae. Br. J. Dermatol. 136:35-42.

25. Chopra A, Maitra B, Korman NJ (1998) Decreased mRNA expression of several basement membrane components in basal cell carcinoma. J. Invest. Dermatol. 110:52-56.

26. Hao J, Yang Y, McDaniel KM, Dalkin BL, Cress ARE, Nagle RB (1996) Differential expression of laminin 5 (alpha 3 beta 3 gamma 2) by human malignant and normal prostate. Am. J. Pathol. 149: 1341-1349.

27. Liang P, Pardee AB (1992) Differential display of eukaryotic messanger RNA by means of the polymerase chain reaction. Science 257:967-971.

28. Sager $R$ (1997) Expression genetics in cancer: Shifting the focus from DNA to RNA. Proc. Natl. Acad. Sci. U.S.A. 94:952-955.

29. Martin KM, Kwan CP, O'Hare MJ, Pardee AB, Sager R (1998) Identification and verification of differential display cDNAs using gene-specific primers and hybridization arrays. Biotechniques 24: 1018-1026.

30. O'Brien W, Stenman G, Sager R (1986) Suppression of tumor growth by senescence in virally transformed human fibroblasts. Proc. Natl. Acad. Sci. U.S.A. 83:8659-8663.

31. Sager R (1991) Senescence as a mode of tumor suppression. Environ. Health Perspect. 93:59-62.

32. Serrano M, Lin AW, McCurrach ME, Beach D, Lowe SW (1997) Oncogenic ras provokes premature cell senescence associated with accumulation of p53 and pl6 $6^{\mathrm{INK} 4 \mathrm{a}}$. Cell 88:593-602.

33. Clarke C, Titley J, Davies S, O'Hare MJ (1994) An immunomagnetic separation method using superparamagnetic (MACS) beads for large-scale purification of human mammary luminal and myoepithelial cells. Epithelial Cell Biol. 3:38-46.

34. Band V, Sager R (1989) Distinctive traits of normal and tumor-derived human mammary epithelial cells expressed in a medium that supports long-term growth of both cell types. Proc. Natl. Acad. Sci. U.S.A. 86:1249-1253.

35. Band V, Zajchowski D, Swisshelm K, et al. (1990) Tumor progression in four mammary epithelial 
cell lines derived from the same patient. Cancer Res. 50:7351-7357.

36. Zhao S, Ooi SL, Pardee AB (1995) New primer strategy improves the precision of differential display. Biotechniques 18:842-850.

37. Martin KM, Kwan CP, Sager R (1997) A directsequencing-based strategy for identifying and cloning cDNAs from differential display gels. In: Liang P, Pardee AB (eds). Methods in Molecular Biology, Differential Display Methods and Protocols. Humana Press, Totowa NJ, pp. 77-85.

38. Chirqwin JM, Przybyla AE, MacDonald RJ, Rutter WJ (1979) Isolation of biologically active ribonucleic acid from sources enriched in ribonuclease. Biochemistry 18:5294.

39. Zajchowski D, Band V, Pauzie N, Tager A, Stampfer MR, Sager R (1988) Expression of growth factors and oncogenes in normal and tumor-derived human mammary epithelial cells. Cancer Res. 48:7041-7047.

40. Marinkovich MP, Lustrum GP, Keene DR, Burgeson RE (1992) The dermis-epidermal junction of human skin contains a novel laminin varient. J. Cell Biol. 119:695-703.

41. Marinkovich MP, Lustrum GP, Burgeson RE (1992) The anchoring filament protein kalinin is synthesized and secreted as a high molecular weight precursor. J. Biol. Chem. 267:17900-17906.

42. Ryan MC, Tizard R, VanDevanter DR, Carter WG (1994) Cloning of the LamA3 gene encoding the $\alpha 3$ chain of the adhesive ligand epiligrin. J. Biol. Chem. 269:22779-22787.

43. Kallunki P, Sainio K, Eddy R, et al. (1992) A truncated laminin chain homologous to the B2 chain: structure, spatial expression, and chromosomal assignment. J. Cell Biol. 119:679-693.

44. Tait L, Soule HD, Russo J (1990) Ultrastructural and immunocytochemical characterization of an immortalized human breast epithelial cell line, MCF-10. Cancer Res. 50:6087-6094.

45. Trask DK, Band V, Zajchowski DA, Yaswen P, Suh $T$, Sager R (1990) Keratins as markers that distinguish normal and tumor-derived mammary epithelial cells. Proc. Natl. Acad. Sci. U.S.A. 87:23192323.

46. Taylor-Papadimitriou J, Berdichevsky F, D'Souza B, Burchell J (1993) Human models of breast cancer. Cancer Surv. 16:59-78.

47. O'Hare MJ, Ormerod MG, Monaghan P, Lane EB, Gusterson BA (1991) Characterization in vitro of luminal and myoepithelial cells isolated from the human mammary gland by cell sorting. Differentiation 46:209-221.

48. Taylor-Papadimitriou J, Stampfer M, Bartek J, Lewis A, Boshell M, Lane EB, Leigh IM (1989) Keratin expression in human mammary epithelial cells cultured from normal and malignant tissue: relation to in vivo phenotypes and influence of medium. J. Cell Sci. 94:403-413.

49. Orian-Rousseau V, Aberdam D, Fontao L, Chevalier L, Meneguzzi G, Kedinger M, Simon-Assmann P (1996) Developmental expression of laminin-5 and HDl in the intestine: epithelial to mesenchymal shift for the laminin gamma-2 chain subunit deposition. Dev. Dyn. 206:12-23.

50. Rudland PS (1993) Epithelial cells and their possible role in the development of the normal and diseased human breast. Histol. Histopathol. 8:385404.

51. Sager R, Anisowicz A, Neveu M, Liang P, Sotiropoulou $G$ (1993) Identification by differential display of alpha 6 integrin as a candidate tumor suppressor gene. FASEB J. 7:964-970.

52. Natali PG, Nicotra MR, Botti C, Mottolese M, Bitotti A, Segutto D (1992) Changes in expression of $\alpha 6 / \beta 4$ integrin heterodimer in primary and metastatic breast cancer. Br. J. Cancer 66:318-322.

53. Koukoulis GK, Howeedy AA, Korhonen M, Virtanen I, Gould VE (1993) Distribution of tenascin, cellular fibronectin and integrin in the normal, hyperplastic and neoplastic breast. J. Submicrosc. Cytol. Pathol. 25:285-295.

54. Howlett AR, Bailey N, Damsky C, Petersen OW, Bissel $M$ (1995) Cellular growth and survival are mediated by $\beta 1$ integrins in normal human breast but not in breast carcinoma. J. Cell Sci. 108:19451957.

55. Sternlicht MD, Barsky SH (1997) The myoepithelial defense: a host defense against cancer. Med. Hypotheses 48:37-46.

56. Sheng S, Carey J, Seftor EA, Dias L, Hendriz MJC, Sager R (1996) Maspin acts at the cell membrane to inhibit invasion and motility of mammary and prostatic cancer cells. Proc. Natl. Acad. Sci. U.S.A. 93:11669-11674.

57. Airenne T, Haakana H, Sainio K, Kallunki T, Kallunki P, Sariola H, Tryggvason K (1996) Structure of the human laminin gamma 2 chain gene ( $L A M C 2)$ : alternative splicing with different tissue distribution of two transcripts. Genomics 32:5464.

58. Gerecke DR, Wagman DW, Champliaud MF, Burgeson RE (1994) The complete primary structure for a novel laminin chain, the laminin Blk chain. J. Biol. Chem. 269:1 1073-1 1080.

59. Masiakowski $P$, Breathnach R, Bloch J, Gannon K, Krust A, Chambon P (1982) Cloning of cDNA sequences of hormone-regulated genes from the MCF-7 human breast cancer cell line. Nucl. Acids Res. 10:7895-7903.

60. Goldberg GI, Eisen AZ, Bauer EA (1988) Tissue stress and tumor promotion. Possible relevance to epidermolysis bullosa. Arch. Dermatol. 124:737-741. 